\title{
The Relationship between Brand-Specific Alcohol Advertising on Television and Brand-Specific Consumption among Underage Youth
}

\author{
Craig S. Ross, MBA, PhD, Emily Maple, MPH, Michael Siegel, MD, MPH, William DeJong, \\ PhD, Timothy S. Naimi, MD, MPH, Joshua Ostroff, BA, Alisa A. Padon, MBE, Dina L.G. \\ Borzekowski, EdD, EdM, MA, and David H. Jernigan, PhD \\ Virtual Media Resources (CSR, JO), Natick, Massachusetts; Department of Community Health \\ Sciences (EM, MS, WD, TSN), Boston University School of Public Health, Boston, \\ Massachusetts; Department of Health, Behavior, and Society (AP, DHJ), Johns Hopkins \\ Bloomberg School of Public Health, Baltimore, Maryland; and Department of Behavioral and \\ Community Health (DLGB), University of Maryland School of Public Health
}

\begin{abstract}
Background-Being able to investigate the relationship between underage drinkers' preferences for particular brands and their exposure to advertising for those brands would represent a significant advance in alcohol marketing research. However, no previous national study has examined the relationship between underage youth exposure to brand-specific alcohol advertising and consumption of those brands.
\end{abstract}

\begin{abstract}
Methods-We conducted a cross-sectional, internet-based survey of a national sample of 1,031 youths, ages 13-20, who had consumed at least one drink of alcohol in the past 30 days. We ascertained all alcohol brands consumed by respondents in the past 30 days. The main outcome measure was brand-specific consumption during the past 30 days, measured as a dichotomous variable. The main predictor variable was exposure to brand-specific alcohol advertising on television. The respondents reported which of 20 television shows popular with youth they had watched during the past 30 days. For each respondent, we calculated a standard measure of potential exposure to the brand-specific alcohol advertising that aired on those shows during the preceding 12 months, based on Nielsen (New York, NY) estimates of the youth audience for each show's telecasts.
\end{abstract}

Results-Compared to no brand-specific advertising exposure, any exposure was associated with an increased likelihood of brand-specific consumption (adjusted odds ratio 3.02; 95\% confidence interval: 2.61-3.49) after controlling for several individual- and brand-level variables. When measured as a continuous variable, the relationship between advertising exposure and brand consumption was nonlinear, with a large association at lower levels of exposure and diminishing incremental effects as the level of exposure increased.

Corresponding Author: Michael Siegel, MD, MPH, Department of Community Health Sciences, Boston University School of Public Health, Crosstown Center, 801 Massachusetts Avenue, $3^{\text {rd }}$ Floor, Boston, MA 02118, Telephone: 617-638-5167, Fax: 617-638-4483, mbsiegel@bu.edu. 
Conclusions-There is a robust relationship between youth's brand-specific exposure to alcohol advertising on television and their consumption of those same alcohol brands during the past 30 days. This study provides further evidence of a strong association between alcohol advertising and youth drinking behavior.

\section{Keywords}

Advertising; Alcohol; Brand; Underage Drinking; Youth

\section{Introduction}

Alcohol use among adolescents and its negative consequences are well documented (USDHHS, 2007). A large proportion of adolescents experiment with alcohol, with $79 \%$ of high school seniors having tried alcohol and $32 \%$ having consumed five or more drinks on one occasion in the past month (CDC, 2013). While many factors increase the risk of underage drinking, including parenting styles (Foxcroft and Lowe, 1991), peer drinking (Mundt, 2011), and personality traits (Wu et al., 2006), multiple longitudinal studies have also shown alcohol advertising to be an independent risk factor for underage drinking (Anderson et al., 2009; Smith and Foxcroft, 2009). Youth are heavily exposed to alcohol advertisements and view an average of 366 alcohol advertisements annually on television alone (CAMY, 2010). Given this high level of exposure, it is important to understand whether and to what extent these advertisements may influence youth alcohol consumption.

Several longitudinal studies suggest that exposure to alcohol advertising and marketing increases the likelihood that adolescents will consume alcohol (Collins et al., 2007; Gordon et al., 2010; Morgenstern, 2011b; Stacy et al., 2004), while other studies have found that increased advertising exposure increases the volume of alcohol consumption (Snyder et al., 2006). Multiple studies have demonstrated how alcohol advertising modifies expectations of alcohol use through a variety of mechanisms including message receptivity, message interpretation, ability to invoke perceived desirability, and brand identification, and that changes in expectations are associated with changes in drinking behavior (Austin et al., 2006; Henriksen et al., 2008; Morgenstern et al., 2011a; McClure et al., 2013).

While these studies have suggested that there is a connection between exposure to alcohol advertising and drinking behavior, the analyses have been conducted at an aggregate level (i.e., total advertising is related to the likelihood of any alcohol consumption or the total amount of alcohol consumed) primarily because there have been little if any published data on specific brands of alcohol that underage drinkers consume. This produces two potential problems. First, if youth only drink a small number of brands, then examining the relationship between aggregate advertising and alcohol consumption might dilute out any true effect, leading to a Type II error.

Second, existing studies lack specificity because they have not shown that youth who are exposed to alcohol advertising actually consume the brands to whose advertisements they are exposed. If youth are exposed to Bud Light advertisements, but initiate drinking with a brand that was not advertised, this hardly seems consistent with the hypothesis that the Bud Light advertising caused the initiation. Finding a relationship between brand-specific 
advertising exposure and the consumption of that precise brand would substantially strengthen the evidence that advertising influences youth drinking behavior.

Recently, we advanced this field of research by conducting a survey of a nationally representative sample of 1,031 underage youth, ages 13 to 20, to assess their alcohol use by specific brand and type (Siegel et al., 2013). The respondents were also asked to identify which of 20 television shows popular with youth they had watched during the past 30 days (Borzekowski et al., 2014). By combining these data with brand-specific advertising exposure data from the same time period, we were able to estimate brand-specific alcohol advertising exposure based on each respondent's television viewing habits. In this paper, we examine for the first time the association between exposure to brand-specific alcohol advertising among underage youth and brand-specific alcohol consumption among those individuals.

\section{Methods}

\section{Design Overview}

Using data from a cross-sectional survey of alcohol brand consumption among underage drinkers, we examined the relationship between seeing advertisements for a specific brand on 20 television programs and consumption of that brand. There were 123 brands advertised during the study period on all television shows, of which 60 were advertised on these 20 television shows. We created a multi-level data set with 123 brand advertising exposure measures and 123 outcome (brand-specific alcohol consumption) measures for each of the 1,031 respondents $(126,813$ observations). For each respondent, the brand exposure measures were based on the gross rating points for 12-20 year-olds by brand, summed across the programs seen by that respondent. The two outcomes were consumption of a specific brand (dichotomous) and the average number of drinks of a brand consumed during the past month (continuous). To account for multiple observations per individual, we used generalized estimating equations (GEE).

\section{Youth Sample}

The sample consisted of 1,031 youths, ages 13-20, recruited from a national, pre-recruited internet panel maintained by Knowledge Networks (Palo Alto, CA), who had consumed at least one drink of alcohol in the past 30 days. The methodology of the Youth Alcohol Brand Survey is detailed elsewhere (Knowledge Networks, 2012).

Briefly, Knowledge Networks maintains a pre-recruited panel of approximately 50,000 adults (including persons ages 18-20) who have agreed to be invited periodically to participate in internet-based surveys. The company sent 18- to 20-year-old panelists an email invitation to participate in the survey. To recruit the 13- to 17-year-olds, the company asked its adult panelists whether they had children in this age group and, if so, whether they would grant permission for them to be surveyed. With the parent's consent, the company sent one of the children (randomly chosen, as necessary) the email invitation. Youth who agreed to participate in the survey were emailed a link to a secure web site where a screening questionnaire determined if the respondent had consumed alcohol in the past 30 
days and was thus eligible for the survey. Those who completed the survey had a $\$ 25$ gift credited to their Knowledge Networks account.

The surveys were carried out between December 2011 and May 2012. For the older youth sample (ages 18-20), the overall response rate was $43.4 \%$. For the younger youth sample (ages 13-17), the overall response rate was $44.4 \%$.

The Institutional Review Board of the Boston University Medical Center approved the study protocol.

The internet-based survey instrument inquired about past 30-day consumption of 898 major brands of alcohol within 16 different alcoholic beverage types. Despite the large number of brands ascertained, we have validated this novel method of collecting alcohol brand consumption data (Siegel et al., 2011).

\section{Weighting Procedures}

Knowledge Networks applied statistical weighting adjustments to account for selection probability, non-response to panel recruitment, and panel attrition. Post-stratification adjustments based on demographic distributions from the Current Population Survey (CPS) conducted by the U.S. Bureau of the Census were made for gender, age, race/ethnicity, census region, household income, home ownership status, metropolitan area, and household size to make the data nationally representative. All analyses employed these study weights.

\section{Advertising Exposure}

To ascertain the respondents' potential exposure to brand-specific alcohol advertising, the survey asked which of 20 television shows they had viewed in the past 30 days (Table 1). The selected shows were the top 20 for underage youth (ages 12-20) exposure to alcohol advertising during the period 2009-2010, as assessed by Nielsen (New York, NY).

Advertising has been shown to have a cumulative effect, with both past advertisements and current advertisements influencing behavior (Broadbent, 2000)). To account for this, advertisers developed a measure of cumulative advertising exposure—called adstock - that sums current advertising exposure levels with prior levels, which are discounted using a "decay rate" to account for the diminishing influence of previous advertising exposures over time (Broadbent, 2000). The decay rate is typically expressed as an advertisement's "halflife," defined as the time period over which half of an advertisement's effect will decay. From a public health perspective, adstock can be thought of as the cumulative "dose" of alcohol advertising exposure at a given point in time.

Advertising for most products has a half-life of 3 to 4 weeks (Broadbent, 1997). While there is some variation in the reported depreciation rate for alcohol advertising specifically, the bulk of the literature supports the assumption of a rapidly decaying effect of alcohol advertising, consistent with Broadbent's finding of a half-life of approximately one month (Clarke, 1976; Grabowski, 1977; Lee and Tremblay, 1992; Nelson, 2001; Selvanathon, 1987). 
To calculate adstock, we started with a measure of per capita advertising exposure called a Gross Rating Point (GRP). Gross Rating Points are calculated by taking the total number of advertisements seen by a given age group and dividing by the size of that age group's total population. In short, the GRP represents the average potential exposure for that population. In this study, GRPs for each television show and for each alcohol brand were derived from data licensed from Nielsen (New York) (Nielsen, 2011-2012).

For each respondent, we calculated adstock for each brand's advertisements on each television show that the respondent reported watching during the past 30 days. We did this by adding the GRPs for each brand on each show during the preceding 12 months, including the month that the respondent completed the survey. We discounted each respondent's previous months' exposure by applying a half-life decay rate of one month to the monthly GRP figures derived from the Nielsen data.

For each respondent, we summed the adstock units for each brand across all 20 television shows to obtain a brand-specific estimate of that respondent's overall exposure, or total adstock.

The above analysis assumes that a respondent consistently watches the same television show over a period of many months. While current television viewing patterns are commonly assumed to reflect patterns over time in the marketing literature, there are studies which demonstrate varying levels of network and program loyalty based on sociodemographic characteristics (Lin et al., 2002; Meyer and Hyndman, 2006; Meyer and Muthaly, 2008). To avoid the assumption that past month viewing accurately predicts viewing over a sustained, previous time period, we conducted a re-analysis of all models using only the self-reported, past month television program exposures.

\section{Outcome Measures}

The main outcome, defined as a dichotomous variable, was whether a respondent reported consuming a given brand within the past 30 days. As a secondary outcome, we used a continuous variable reflecting the volume of brand-specific alcohol consumption: the average number of drinks of that brand consumed during the past month.

\section{Brands Included in Analysis}

We included in the analysis all 123 alcohol brands that were advertised nationally on any television show during the period January 2011 through May 2012. Since the first interviews were conducted in December 2011, going back 11 months from that point ensured that, with a depreciation rate of $50 \%$ per month, we would capture essentially $100 \%$ of the adstock for all respondents. About half of the 123 brands (61) were advertised on one or more of the 20 selected television shows, and about half (62) were not. The top 10 brands in terms of aggregated youth exposure across the 20 television shows were (in descending order): Samuel Adams, Absolut, Bud Light, Jameson Irish Whiskey, Grand Marnier, Disaronno Amaretto, Stella Artois, Yellow Tail, Dos Equis, and Heineken. The top five brands in terms of underage youth GRPs for each show are listed in Table 1. 


\section{Covariates}

To address the possibility of confounding by variables that may be related both to youth brand-specific consumption and television viewing patterns, we controlled for the following individual-level factors: age, gender, race/ethnicity, household income, home ownership status, internet access, region, residence (rural vs. non-rural area), binge drinking, parental drinking, and risk-taking (measured by seat belt use). We also controlled for autonomy of brand choice - that is, how often the respondent made the decision about the brand consumed as opposed to someone else making that decision. Finally, at the individual level, we controlled for general media use patterns. In a previous paper, we used a latent class analysis to examine the respondents' television viewing and magazine readership patterns, which resulted in the identification of four such distinct clusters (Borzekowski et al., 2014). Thus, the analysis included a set of three dummy variables that worked in combination to define each respondent's media cluster. To control for general media use patterns, we included in the model the number of hours of television viewing on a typical weekday.

To address the possibility that youth brand choices simply mimic those of adults, we controlled for the estimated overall market share for each alcohol brand, as calculated from Impact Databank (M. Shanken Communications, New York, NY) estimates of the annual wholesale shipments of each alcohol brand in 2010 (Impact Databank, 2011a, 2011b, 2011c). To address the possibility that youth are simply choosing the cheapest brands, we controlled for the average price per ounce of ethanol for each alcohol brand, as ascertained using a systematic internet pricing protocol (DiLoreto et al., 2012).

\section{Analysis}

Our final data set consisted of paired observations of alcohol brand consumption and potential advertising exposure. For each respondent, we created a record for each of the 123 brands that consisted of 1) whether that youth consumed that brand in the past 30 days (consumption); and 2) the total adstock for that brand's advertising on the television shows the respondent reported having watched in the past 30 days (potential advertising exposure). With 1,031 respondents and 123 brands, there were a total of 126,813 observations in the data set.

Since the main outcome variable of brand consumption was dichotomous, we modeled the relationship between consumption and exposure using logistic regression analysis. We used a generalized estimating equations (GEE) approach to account for the clustering of multiple observations among individual respondents (Liang and Zeger, 1986), thereby avoiding a Type I error that would be potentially introduced if this correlation were ignored (Hedeker et al., 1994). We used an exchangeable (compound symmetry) working correlation matrix to model the correlation among observations within individuals. We also used robust variance estimators, which produce consistent point estimates (Hedeker et al., 1994; Pendergast et al., 1996) and standard errors (Hedeker et al., 1994; Horton and Lipsitz, 1999; Pendergast et al., 1996), even if the working correlation matrix is misspecified.

For the secondary outcome - number of drinks of each brand during the past month - the outcome variable was continuous. Because this variable was not normally distributed (it 
represents a count variable and is highly skewed towards zero), we modeled it using a negative binomial regression, along with GEE to account for the multiple observations per individual.

In the first models, we treated potential advertising exposure as dichotomous - that is, any brand exposure versus no brand exposure. Next, we treated exposure as a continuous variable to estimate the effect of the amount of brand-specific advertising exposure on brand consumption. Multiple research studies of advertising effects have shown that the association between advertising levels and consumption is non-linear, with diminishing marginal returns at higher levels of exposure (Ackoff and Emshoff, 1975; Saffer, 2002; Wind and Sharp, 2009). Accordingly, we considered applying a natural log transformation to the adstock variable before entering it into the model as a continuous variable. We made no a priori assumptions about the "dose-response" relationship and in exploratory analyses, examined the goodness of fit of both linear and curvilinear models. Based on the Akaike Information Criterion (AIC), we judged the curvilinear model with the log-transformed adstock measure to best fit the data.

\section{Results}

The prevalence of exposure to specific television shows for the sample population is shown in Table 1. The prevalence of watching individual programs ranged from $6.0 \%$ to $34.0 \%$, with a total of between 17 and 43 individual brands advertised on each show during the 17month period.

The distribution of individual adstock among the 1,031 respondents ranged from 0 GRPs to 55.5 GRPs, with a mean of 0.8 and a standard deviation of 2.7. For advertised brands, the average exposure ranged from 0.0002 GRPs to 7.6 GRPs, with a mean of 1.7 and a standard deviation of 1.9 .

\section{Analyses with Any Brand Consumption (Dichotomous) as Outcome}

In an initial analysis, we modeled the relationship between consumption of a brand (yes vs. no) and advertising exposure (any exposure vs. no exposure) (Table 2). The odds ratio for brand-specific consumption based on exposure to brand-specific advertising was 3.02 (95\% CI: $2.61,3.49$, p <0.001) after controlling for the individual- and brand-level variables listed in Table 2.

We repeated this analysis after excluding the 62 brands that were not advertised on any of the 20 television shows. The relationship between brand-specific advertising exposure and brand consumption remained positive and significant ( $\mathrm{OR}=1.52 ; 95 \% \mathrm{CI}, 1.28-1.82)$ (data not shown).

We then repeated the analysis using only current month advertising exposure. The relationship between brand-specific advertising exposure and brand consumption remained positive and significant ( $\mathrm{OR}=2.15 ; 95 \% \mathrm{CI}, 1.82-2.53$ ) (data not shown, all 123 brands included). After excluding the 62 brands that were not advertised on any of the 20 television 
shows, the relationship between brand-specific current advertising exposure and brand consumption remained positive and significant $(\mathrm{OR}=1.38$; 95\% CI, 1.19-1.60).

We then modeled the relationship between consumption of a brand (again a dichotomous variable) and exposure measured as a continuous variable. The results indicated that exposure is a significant predictor of brand consumption, and that the relationship between exposure and brand consumption is logarithmic: the odds of consumption increased dramatically at lower levels of exposure and then reached a point where subsequent increases in exposure resulted in smaller increases in the odds of consumption (Figure 1).

Specifically, with 0 to 5 adstock units of exposure, the adjusted odds of drinking the advertised brand increased by 1.21 (95\% confidence interval: $1.18,1.24)$, or $21 \%$ over this 5-unit range. Moving to a range of 5 to 10 adstock units, the odds of drinking the advertised brand increased again by only $1.07(1.06,1.08)$ over this 5-unit range, and with a range of 10 to 15 adstock units, the odds increased yet again by only $1.04(1.03,1.05)$ over this 5 -unit range. For youth exposed to relatively high levels of brand advertising, from 45 to 50 adstock units, the odds of drinking the advertised brand increased again by only 1.01 (1.01, 1.01) over this 5-unit range.

Even though the adjusted analyses had controlled for overall brand market share, we conducted an additional analysis to further rule out the possibility that youth are merely mimicking adults by choosing the most popular overall brands, which may also happen to be the most heavily advertised. To do this, we repeated the GEE logistic regression analyses, but stratified the analysis by overall brand market share (Table 3 ). The relationship between advertising exposure and brand consumption held even when we restricted this analysis to the top 25,14 , or 10 brands by overall market share.

\section{Analyses with Number of Drinks of Brand in Past 30 Days as Outcome Variable}

For the continuous outcome variable-number of drinks of a brand consumed in the past 30 days - the negative binomial models revealed a positive and significant relationship between brand-specific advertising exposure and volume of the brand consumed (Table 4). For any exposure to a brand's advertisements (i.e., adstock greater than zero), the incidence rate ratio (IRR) was 3.35 (95\% CI, 2.31-4.87), indicating that youths who saw advertisements for a particular brand consumed 3.4 times as many drinks of that brand during the past 30 days. For exposure to a brand's advertising during the current month, the incidence rate ratio was 2.39 (95\% CI, 1.54-3.72), indicating that youths who saw advertisements for a particular brand in the current month consumed 2.4 times as many drinks of that brand during the past 30 days.

In a final analysis, we modeled the number of drinks of a particular brand consumed in a given month, entering brand-specific advertising exposure as a continuous measure. The relationship between brand-specific advertising exposure and the number of drinks consumed was curvilinear. Specifically, with 0 to 5 adstock units of exposure, the number of drinks per month of the advertised brand increased by a factor of 1.24 (95\% confidence interval: $1.17,1.32$ ) over this 5 -unit range. Moving to a range of 5 to 10 adstock units, the number of drinks per month of the advertised brand increased again by a factor of only 1.08 
$(1.05,1.10)$ over this 5 -unit range. For youth exposed to relatively high levels of brand advertising, from 45 to 50 adstock units, the number of drinks per month of the advertised brand increased again by a factor of only $1.01(1.01,1.02)$ over this 5 -unit range.

\section{Discussion}

To the best of our knowledge, this is the first study to describe the relationship between exposure to brand-specific alcohol advertising and consumption of those specific brands among a national sample of underage drinkers. We found a robust relationship between brand-specific exposure to advertising on television, based on the respondents' self-reports of the television shows they viewed in the past 30 days, and their consumption of those alcohol brands during the past 30 days. This relationship was significant even after controlling for a range of individual- and brand-level variables, including demographic characteristics, magnitude of alcohol consumption, parental drinking, risk-taking behavior, media use patterns, autonomy of brand choice, brand-specific prices, and overall brand market share. Thus, this paper establishes a link between alcohol advertising and consumption of specific brands among underage youth.

This study presents novel evidence of the association between alcohol advertising and youth alcohol consumption. While several previous studies have revealed a relationship between overall youth advertising exposure and the initiation of alcohol use, they did not demonstrate that youth actually drink the brands they see advertised most frequently. By demonstrating a direct link between advertising exposure and behavior at the brand level, our findings greatly improve the specificity of the association between alcohol advertising and alcohol consumption among underage youth.

Because our study is cross-sectional, we cannot determine the direction of the association between brand-specific alcohol advertising exposure and brand-specific consumption. One question is whether youth who are already drinking a specific brand are more likely to seek out and watch programming that is likely to include advertising for that brand. That seems highly unlikely. Also note that the study design controlled for the respondents' media use patterns by controlling for each respondent's media use cluster (Borzekowski et al., 2014) and overall television viewing frequency. Therefore we believe our findings do provide evidence to suggest that advertising is influencing drinking behaviors and not the other way around.

One theoretical alternative explanation for these study findings is that youth are merely mimicking the brand choices of adults and that the brands consumed most heavily by adults are precisely those with higher advertising levels. In other words, it could be that alcohol advertising affects adult brand decisions and that youth merely model adult behavior, thus creating a spurious relationship between youth exposure to alcohol advertising and youth brand choices. There are two reasons why we do not believe this explains our findings. First, we controlled directly for the overall market share of each brand in our model. Second, the relationship between individual brand-specific advertising exposure and brand consumption held even when we restricted the analysis to only those brands that are highly popular among adults (i.e., the top 25,14 , or 10 brands in terms of overall market share). 
The logarithmic relationship between advertising exposure and brand consumption that we observed (Figure 1) is consistent with previous advertising research and theory. As explained in the Vidale-Wolfe model, advertising effects decrease with increasing intensity due to saturation (Burrato et al., 2006; Vidale and Wolfe, 1957), thus producing a decreasing or concave slope as the number of advertising units increase (Little, 1979). In other words, the first advertising unit is the most effective, followed by the second, third, and so forth (Vidale and Wolfe, 1957), consistent with the law of diminishing returns (Little, 1979). Several previous econometric studies have demonstrated a non-linear response between advertising and drinking behavior (Ackoff and Emshoff, 1975; Wind and Sharp, 2009). Most studies, however, have examined the association using a strictly linear treatment of the advertising exposure variable. We recommend that researchers take a fresh look at these prior studies by examining non-linear associations.

One might argue that since our study suggests a link between brand-specific advertising exposure and brand choices among underage drinkers, it reinforces the alcohol industry argument that advertising affects brand choice but not alcohol consumption. There are two problems with this argument. First, the alcohol industry has not acknowledged that alcohol advertising influences underage youth in any way. Thus, a finding that advertising exposure affects youth brand choices would conflict with the industry's public assertions. Second, it is implausible that advertising for a specific brand could affect perceptions, attitudes, and beliefs in such a way as to promote positive images of that brand, but without promoting the same positive perceptions, attitudes, and beliefs about drinking in general (Pollay et al., 1996). As Pollay et al. (1996, p. 11) argue with regard to cigarettes: "Advertising that makes a cigarette brand attractive inevitably also makes cigarette smoking attractive, at least the smoking of that brand." There is no reason to believe this is not the case with alcohol advertising as well.

It appears that the observed relationship between advertising exposure and alcohol brand choice is driven largely by our finding that underage youth tend not to drink non-advertised brands. Most of the brands not advertised on the 20 television shows were not consumed by the youth drinkers in our sample. This served to drive the odds ratio away from the null, as these brands figured prominently in the negative exposure/negative outcome cell. As expected, with these brands excluded, the odds ratio recedes closer to the null, dropping from about 3.0 to 1.5 .

This study is subject to several limitations in addition to the potential problem of reverse causation. First, our measure of advertising exposure is based on the respondents' selfreported television viewing patterns during the past 30 days. We measured potential exposure, not documented exposure. Also, we captured a snapshot of each youth's television viewing for one month, which may not have been representative of their actual viewership during earlier months.

Second, there are different formats for viewing television programs, and advertising can differ based on the medium in which a program is viewed. Our calculations of adstock are based on an assumption that youth viewed the reported programs on television, not via the internet. Furthermore, some youth may view programs using a DVR, which allows them to 
skip over advertisements. Youth who are more interested in alcohol may be less likely to skip over the ads.

Third, this analysis examined alcohol advertising on a sample of only 20 television shows, which may represent a small proportion of any given young person's overall exposure to alcohol advertising. For example, we did not collect data on youth exposure to radio, print, or outdoor ads, to internet advertising, or to alcohol brand portrayals in movies.

Fourth, while we controlled for overall brand market share, these data were from 2010, while the survey was conducted from December 2011 to May 2012. It is possible that market shares changed over time, so we may not have adequately controlled for this variable.

Finally, while we controlled for a number of factors that would be expected to correlate with both brand consumption and brand advertising exposure on television, it remains possible that there is an unmeasured confounder that we failed to capture or did not capture adequately. Therefore, these findings need to be confirmed in other studies.

Despite these limitations, this analysis provides evidence that exposure to brand-specific advertising on television is associated with an increased likelihood of underage youth drinkers consuming the advertised brands. By demonstrating a specific and direct association at the brand level, this study adds significantly to the growing body of evidence linking alcohol advertising with youth drinking behavior. Future research should attempt to replicate these findings using a longitudinal design and with documentation of actual exposure to alcohol advertising.

\section{Acknowledgments}

This research was supported by a grant from the National Institute on Alcohol Abuse and Alcoholism (R01 AA020309-01). Craig Ross's participation was funded in part by the Boston University Reproductive, Perinatal, and Pediatric Epidemiology Training Program (T32 HD052458).

\section{References}

Ackoff RL, Emshoff JR. Advertising research at Anheuser-Busch, Inc. (1963-68). Slone Management Review. 1975; 16:1-15.

Anderson P, deBrujin A, Angus K, Gordon R, Hastings G. Impact of alcohol advertising and media exposure on adolescent alcohol use: a systematic review of longitudinal studies. Alcohol Alcohol. 2009; 44:229-243. [PubMed: 19144976]

Austin EW, Chen MJ, Grube JW. How does alcohol advertising influence underage drinking? The role of desirability, identification and skepticism. J Adolesc Health. 2006; 38:376-384. [PubMed: 16549298]

Borzekowski D, Ross C, Jernigan D, DeJong W, Siegel M. The relationship between patterns of media use and alcohol brand consumption among underage drinking youth in the US Pediatrics. 2014 in press.

Broadbent, S. Accountable Advertising: A Handbook for Managers and Analysts. Admap Publications; Henley-on-Thames, UK: 1997.

Broadbent S. What do advertisements really do for brands? International Journal of Advertising. 2000; 19:147-165.

Burrato A, Grosset L, Bruno V. Linear models and advertising. Automatica. 2006; 42:1343-1347. 
Center on Alcohol Marketing and Youth (CAMY). Baltimore, MD: 2010. Youth Exposure to Alcohol Advertising on Television, 2001-2009. Available at: http://www.camy.org/sebin/u/r/ CAMYReport2001_2009.pdf [Accessed March 27, 2013]

Centers for Disease Control and Prevention (CDC). Youth Risk Behavior Surveillance System. Atlanta, GA: Centers for Disease Control and Prevention, Division of Adolescent and School Health; 2013. Available at: http://www.cdc.gov/healthyyouth/yrbs/index.htm [Accessed March 27, 2013]

Clarke DG. Econometric measurement of the duration of advertising effect on sales. J Mark Res. 1976; 13:345-357.

Collins RL, Ellickson PL, McCaffrey D, Habarsoomians K. Early adolescent exposure to alcohol advertising and its relationship to underage drinking. J Adolesc Health. 2007; 40:527-534. [PubMed: 17531759]

DiLoreto JT, Siegel M, Hinchey D, Valerio H, Kinzel K, Lee S, Chen K, Shoaff JR, Kenney J, Jernigan DH, DeJong W. Assessment of the average price and ethanol content of alcoholic beverages by brand-United States, 2011. Alcohol Clin Exp Res. 2012; 36:1288-1297. [PubMed: 22316218]

Foxcroft DR, Lowe G. Adolescent drinking behaviour and family socialization factors: a metaanalysis. J Adolesc. 1991; 14:255-273. [PubMed: 1835984]

Gordon R, MacKintosh AM, Moodie C. The impact of alcohol marketing on youth drinking behavior: a two-stage cohort study. Alcohol Alcohol. 2010; 45:470-480. [PubMed: 20739441]

Grabowski HG. The effects of advertising on intra-industry shifts in demand. Explorations in Economic Research. 1977; 4:675-701.

Hedeker D, Gibbons RD, Flay BR. Random-effects regression models for clustered data with an example from smoking prevention research. J Consult Clin Psychol. 1994; 62:757-765. [PubMed: 7962879]

Henriksen L, Feighert EC, Schleicher NC, Fortmann SP. Receptivity to alcohol marketing predicts initiation of alcohol use. J Adolesc Health. 2008; 42:28-35. [PubMed: 18155027]

Horton NJ, Lipsitz SR. Review of software to fit generalized estimating equation regression models. Am Stat. 1999; 53:160-169.

Impact Databank. The US Distilled Spirits Market: Impact Databank Review and Forecast. 2011. New York: M. Shanken Communications; 2011a.

Impact Databank. The US Beer Market: Impact Databank Review and Forecast. 2011. New York: M. Shanken Communications; 2011b.

Impact Databank. The US Distilled Wine Market: Impact Databank Review and Forecast. 2011. New York: M. Shanken Communications; 2011c.

Jorgensen S. A survey of some differential games in advertising. Journal of Economic Dynamics and Control. 1982; 4:341-369.

Knowledge Networks. Menlo Park, CA: 2012. KnowledgePanel ${ }^{\circledR}$ Design Summary. Available at: http://www.knowledgenetworks.com/knpanel/docs/KnowledgePanel\%28R\%29-Design-SummaryDescription.pdf [Accessed April 7, 2013]

Lee B, Tremblay VJ. Advertising and the US market demand for beer. Appl Econ. 1992; 24:69-76.

Liang KY, Zeger SL. Longitudinal data analysis using generalized linear models. Biometrika. 1986; 73:13-22.

Lin CA, Atkin DJ, Abelman R. The influence of network branding on audience affinity for network television. J Advert Res. 2002; 42:19-32.

Little JDC. Advertising models: The state of the art. Operations Research. 1979; 27:629-667.

McClure AC, Stoolmiller M, Tanski SE, Engels RC, Sargent JD. Alcohol marketing receptivity, marketing-specific cognitions, and underage binge drinking. Alc Clin Exp Res. 2013; 37(S1):E404-E413.

Meyer D, Hyndman RJ. The accuracy of television network rating forecasts: The effects of data aggregation and alternative models. Model Assist Stat Appl. 2006; 1:147-155.

Meyer D, Muthaly S. New measures and a new model for television network loyalty (MOTNL). Marketing Bulletin. 2008; 19:1-19. 
Morgenstern M, Isensee B, Sargent JD, Hanewinkel R. Attitudes as mediators of the longitudinal association between alcohol advertising and youth drinking. Arch Pediatr Adolesc Med. 2011a; 165:610-616. [PubMed: 21383258]

Morgenstern M, Isensee B, Sargent JD, Hanewinkel R. Exposure to alcohol advertising and teen drinking. Prev Med. 2011b; 52:146-151. [PubMed: 21130108]

Mundt MP. The impact of peer social networks on adolescent alcohol use initiation. Acad Pediatr. 2011; 11:414-421. [PubMed: 21795133]

Nelson, JP. Alcohol advertising and alcohol bans: A survey of research methods, results, and policy implications. In: Baye, MR.; Nelson, JP., editors. Alcohol and Differentiated Products. Vol. 10. Elsevier Science Ltd.; Oxford: 2001. p. 239-295.

Nielsen. Copyright 2011-2012 Nielsen Ratings and other data contained herein are the copyrighted property of Nielsen Unauthorized use of this copyrighted material is expressly prohibited Violators may be subject to criminal and civil penalties under federal law (17 USC 101 et seq) All rights reserved. The Nielsen Company; 2011-2012. 2011-2012

Pendergast JF, Gange SJ, Newton MA, Lindstrom MJ, Palta M, Fisher MR. A survey of methods for analyzing clustered binary response data. Int Stat Rev. 1996; 64:89-118.

Pollay RW, Siddarth S, Siegel M, Haddix A, Merritt RK, Giovino GA, Eriksen MP. The last straw? Cigarette advertising and realized market shares among youths and adults, 1979-1993. J Mark. 1996; 60:1-16.

Saffer H. Alcohol advertising and youth. J Stud Alcohol. 2002; S14:173-181.

Selvanathon, EA. Advertising and Consumption: A New Approach with an Application to Alcohol. Nedlands, Western Australia: Department of Economics, University of Western Australia; 1987.

Siegel M, DeJong W, Naimi TS, Fortunato EK, Albers AB, Heeren T, Rosenbloom DL, Ross C, Ostroff J, Rodkin S, King C, Borzekowski DL, Rimal RN, Padon AA, Eck RH, Jernigan DH. Brand-specific consumption of alcohol among underage youth in the United States. Alc Clin Exp Res. 2013; 37:1195-1203.

Siegel M, DeJong W, Naimi TS, Heeren T, Rosenbloom DL, Ross C, Ostroff J, Jernigan DH. Alcohol brand preferences of underage youth: Results from a pilot survey among a national sample. Subst Abuse. 2011; 32:191-201.

Smith LA, Foxcroft DR. The effect of alcohol advertising, marketing and portrayal on drinking behavior in young people: a systematic review of prospective cohort studies. BMC Public Health. 2009; 9:51. [PubMed: 19200352]

Snyder LB, Milici F, Slater M, Sun H, Strizhakova Y. Effects of alcohol advertising exposure on drinking among youth. Arch Pediatr Adolesc Med. 2006; 160:18-24. [PubMed: 16389206]

Stacy AW, Zogg JB, Unger JB, Dent CW. Exposure to televised alcohol ads and subsequent adolescent alcohol use. Am J Health Behav. 2004; 28:498-509. [PubMed: 15569584]

U.S. Department of Health and Human Services (USDHHS). Rockville, MD: U.S. Department of Health and Human Services, Public Health Service, Office of the Surgeon General; 2007. The Surgeon General's Call to Action to Prevent and Reduce Underage Drinking 2007. Available at: http://www.surgeongeneral.gov/library/calls/underagedrinking/calltoaction.pdf [Accessed July 30, 2013]

Vidale ML, Wolfe HB. An operations-research study of sales response to advertising. Operations Research. 1957; 5:370-381.

Wind J, Sharp B. Advertising empirical generalizations: implications for research and action. J Advert Res. 2009; 49:246-252.

Wu P, Bird HR, Liu X, Fan B, Fuller C, Shen S, Duarte CS, Canino GJ. Childhood depressive symptoms and early onset of alcohol use. Pediatr. 2006; 118:1907-1915. 


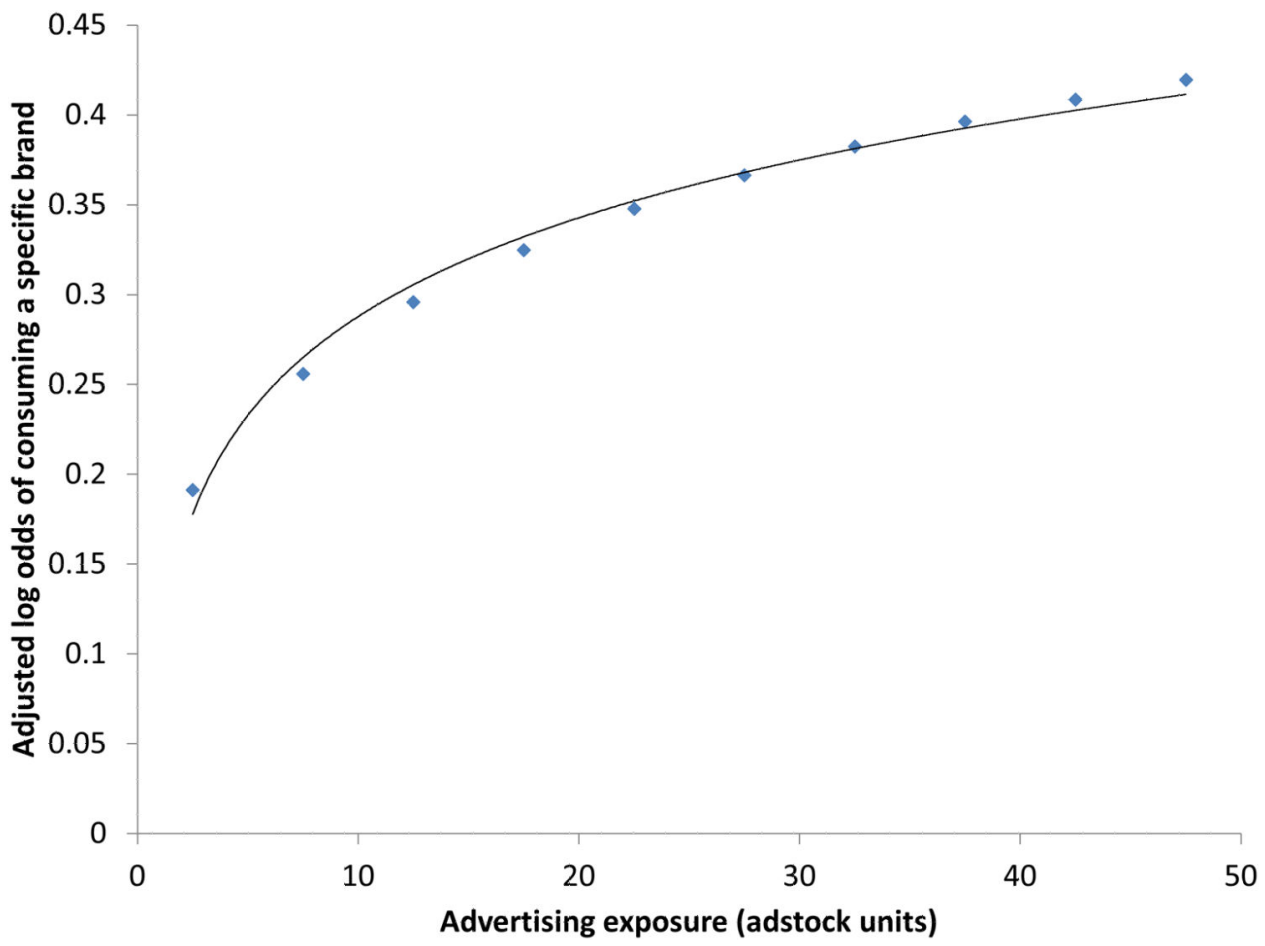

Figure 1.

Log Odds of Brand-specific Consumption at Different Levels of Brand-specific Advertising Exposure This figure shows the likelihood of a youth consuming a particular brand as a function of the youth's level of exposure to advertisements for that brand on one or more of the 20 television shows for which viewing was ascertained. Adstock units represent a measure of cumulative exposure in the month of the youth interview and the preceding months, with an advertising half-life of one month. 
Table 1

Youth exposure to alcohol advertising by specific television show, January 2011 - May 2012

\begin{tabular}{|c|c|c|c|}
\hline & $\%$ Exposed $^{a}$ & $\begin{array}{l}\text { Number of Brands } \\
\text { Advertised }^{b}\end{array}$ & Top Five Brands by Underage Youth GRPs \\
\hline Two and a Half Men & 34.0 & 34 & Sam Adams, MGD Light, Michelob Ultra, Miller Lite, Bud Light \\
\hline Tosh.O & 30.0 & 37 & Corona, Bud Light, Grey Goose, Keystone Light, Miller Lite \\
\hline 1000 Ways to Die & 28.5 & 26 & Sam Adams, Captain Morgan, Miller Lite, Coors Light, Keystone Light \\
\hline Law and Order: SVU & 27.6 & 20 & Stella Artois, Michelob Ultra, Bud Light, Kahlua, Smirnoff vodka \\
\hline CSI & 25.3 & 18 & Stella Artois, Grand Marnier, Grey Goose, Michelob Ultra, Bud Light \\
\hline NCIS & 24.8 & 17 & Stella Artois, Michelob Ultra, Grey Goose, Bud Light, Grand Marnier \\
\hline Man v. Food & 23.0 & 24 & Mikes, Budweiser Select, Heineken, Dos Equis, Michelob Ultra \\
\hline Comedy Central Presents & 22.2 & 31 & MGD Light, Michelob Ultra, Captain Morgan, Bud Light, Mikes \\
\hline Mythbusters & 21.1 & 34 & MGD Light, Sam Adams, Dos Equis, Heineken, Bud Light \\
\hline The Office & 20.5 & 36 & MGD Light, Sam Adams, Bud Light, Malibu, Absolut \\
\hline DVD on TV & 19.4 & 35 & Dos Equis, MGD Light, Sam Adams, Heineken, Ketel One \\
\hline The Daily Show & 15.3 & 43 & MGD Light, Corona, Sam Adams, Bud Light, Heineken \\
\hline Dirty Jobs & 15.0 & 25 & Maker's Mark, Blue Moon, Dos Equis, Jeremiah Weed, Absolut \\
\hline King of Queens & 14.9 & 42 & Sam Adams, MGD Light, Smirnoff vodka, Bud Light, Sauza \\
\hline The Colbert Report & 14.7 & 43 & Bud Light, MGD Light, Corona, Sam Adams, Coors Light \\
\hline Chelsea Lately & 11.9 & 28 & MGD Light, Malibu, Svedka, Disaronno, Budweiser Select \\
\hline Ghost Adventures & 10.3 & 24 & Budweiser Select, MGD Light, Grand Marnier, Disaronno, Dos Equis \\
\hline Ultimate Fighter Unleashed & 9.2 & 26 & Corona, Miller Lite, Southern Comfort, Bud Light, Grand Marnier \\
\hline Deadliest Warrior & 7.4 & 21 & Sam Adams, Malibu, Jeremiah Week, Miller Lite, Captain Morgan \\
\hline Lopez Tonight & 6.0 & 21 & Corona, Sam Adams, Miller Lite, Mikes, Smirnoff vodka \\
\hline
\end{tabular}


Table 2

Odds ratios for brand-specific youth alcohol consumption based on brand-specific advertising exposure (any vs. none) and individual- and brand-level covariates

\begin{tabular}{|c|c|c|c|c|}
\hline Variable & Percentage $^{a}$ & Adjusted Odds Ratio $b$ & $95 \% \mathrm{CI}$ & p-value \\
\hline \multicolumn{5}{|l|}{ Main predictor variable } \\
\hline No exposure & 70.9 & 1.00 & - & \\
\hline Any exposure & 29.1 & 3.02 & $2.61,3.49$ & $<.0001$ \\
\hline \multicolumn{5}{|c|}{ Individual-level variables } \\
\hline \multicolumn{5}{|l|}{ Age } \\
\hline $13-15$ & 10.5 & 1.00 & - & \\
\hline $16-18$ & 37.9 & 0.97 & $0.71,1.32$ & 0.85 \\
\hline $19-20$ & 51.6 & 1.28 & $0.94,1.75$ & 0.11 \\
\hline \multicolumn{5}{|l|}{ Gender } \\
\hline Male & 50.9 & 1.00 & - & \\
\hline Female & 49.1 & 0.80 & $0.65,0.99$ & 0.04 \\
\hline \multicolumn{5}{|l|}{ Race/Ethnicity } \\
\hline White, non-Hispanic & 57.1 & 1.00 & - & \\
\hline Black & 10.6 & 1.00 & $0.69,1.43$ & 0.99 \\
\hline Hispanic & 23.6 & 1.15 & $0.85,1.54$ & 0.37 \\
\hline Other & 8.7 & 1.44 & $0.94,2.20$ & 0.09 \\
\hline \multicolumn{5}{|l|}{ Income } \\
\hline$>\$ 15,000$ & 15.3 & 1.00 & - & \\
\hline$\$ 15,000-\$ 39,999$ & 19.2 & 1.29 & $0.85,1.96$ & 0.23 \\
\hline$\$ 40,000-\$ 99,999$ & 41.7 & 1.31 & $0.84,2.04$ & 0.23 \\
\hline$\$ 100,000$ or more & 23.8 & 1.67 & $1.07,2.62$ & 0.02 \\
\hline \multicolumn{5}{|l|}{ Internet access } \\
\hline No & 6.9 & 1.00 & - & \\
\hline Yes & 93.1 & 1.07 & $0.78,1.47$ & 0.69 \\
\hline \multicolumn{5}{|l|}{ Homeownership } \\
\hline Own & 68.0 & 1.00 & - & \\
\hline Rent & 32.0 & 1.47 & $1.13,1.90$ & 0.004 \\
\hline \multicolumn{5}{|l|}{ Region } \\
\hline Northeast & 19.6 & 1.00 & - & \\
\hline Midwest & 24.4 & 1.16 & $0.86,1.56$ & 0.34 \\
\hline South & 32.1 & 1.08 & $0.82,1.42$ & 0.57 \\
\hline West & 23.9 & 1.00 & $0.75,1.34$ & 0.98 \\
\hline \multicolumn{5}{|l|}{ Metropolitan Area Status } \\
\hline Urban & 85.3 & 1.00 & - & \\
\hline Rural & 14.7 & 0.84 & $0.65,1.09$ & 0.19 \\
\hline \multicolumn{5}{|c|}{ Parent, guardian, or adult caretaker drinks/drank alcohol } \\
\hline No & 38.3 & 1.00 & - & \\
\hline Yes & 61.7 & 0.89 & $0.73,1.08$ & 0.24 \\
\hline
\end{tabular}




\begin{tabular}{|c|c|c|c|c|}
\hline Variable & Percentage ${ }^{a}$ & Adjusted Odds Ratio $b$ & $95 \% \mathrm{CI}$ & p-value \\
\hline \multicolumn{5}{|l|}{ Any heavy episodic ("binge") drinking } \\
\hline No & 46.5 & 1.00 & - & \\
\hline Yes & 53.5 & 2.94 & $2.39,3.63$ & $<.0001$ \\
\hline \multicolumn{5}{|l|}{ Frequency of seat belt use } \\
\hline Never, rarely, or sometime & 90.9 & 1.00 & - & \\
\hline Most of the time or always & 9.1 & 0.92 & $0.65,1.31$ & 0.64 \\
\hline \multicolumn{5}{|c|}{ Frequency of choosing the brand of alcohol } \\
\hline Never, sometimes, or half the time & 63.7 & 1.00 & - & \\
\hline Usually or always & 36.3 & 1.13 & $0.92,1.39$ & 0.24 \\
\hline \multicolumn{5}{|l|}{ Media Cluster } \\
\hline General Audience & 69.0 & 1.00 & - & \\
\hline Celebrity Watchers & 17.0 & 1.34 & $1.07,1.67$ & 0.01 \\
\hline Heavy Mainstream Media Users & 9.8 & 1.49 & $1.08,2.07$ & 0.02 \\
\hline Late Night Cable Viewers & 4.2 & 0.91 & $0.61,1.34$ & 0.62 \\
\hline \multicolumn{5}{|l|}{ Hours of Television Viewing/Weekday } \\
\hline 1 Hour or Less & 28.1 & 1.00 & - & \\
\hline $1.5-2$ Hours & 23.8 & 1.11 & $0.80,1.55$ & 0.53 \\
\hline 3 - 4 Hours & 27.5 & 1.06 & $0.83,1.37$ & 0.63 \\
\hline$>4$ Hours & 20.6 & 1.15 & $0.84,1.56$ & 0.38 \\
\hline \multicolumn{5}{|l|}{ Brand-level Variables } \\
\hline Overall Market Share ${ }^{c}$ & - & 1.29 & $1.26,1.33$ & $<.0001$ \\
\hline Average Price per Ounce of Alcohol $d$ & - & 0.79 & $0.73,0.87$ & $<.0001$ \\
\hline $\begin{array}{l}\text { Weighted percentage of survey respond } \\
\text { All odds ratios in the table are adjusted }\end{array}$ & $\begin{array}{l}\text { he variable. } \\
\text { variables. }\end{array}$ & & & \\
\hline
\end{tabular}


Table 3

Odds of brand-specific alcohol consumption as a function of exposure to brand-specific alcohol advertising on television (yes/no), stratified by overall brand market share

\begin{tabular}{|c|c|c|c|c|}
\hline Brand Market Share (\%) & Observations & Odds Ratio $b$ & $95 \% \mathrm{CI}$ & p-value \\
\hline$<0.5(\mathrm{~N}=$ bottom 98 brands $)$ & 90,944 & 3.25 & $2.69,3.93$ & $<0.0001$ \\
\hline$>0.5(\mathrm{~N}=$ top 25 brands $)$ & 23,200 & 2.62 & $2.19,3.14$ & $<0.0001$ \\
\hline$<1.0(\mathrm{~N}=$ bottom 109 brands $)$ & 101,152 & 3.37 & $2.84,4.00$ & $<0.0001$ \\
\hline$>1.0(\mathrm{~N}=$ top 14 brands $)$ & 12,992 & 2.32 & $1.87,2.88$ & $<0.0001$ \\
\hline$<1.5(\mathrm{~N}=$ bottom 113 brands $)$ & 104,864 & 3.56 & $3.03,4.17$ & $<0.0001$ \\
\hline$>1.5(\mathrm{~N}=$ top 10 brands $)$ & 9,280 & 2.91 & $2.31,3.68$ & $<0.0001$ \\
\hline
\end{tabular}

${ }^{a}$ Overall market share for brand, based on Impact Databank wholesale shipment data.

adjusted for individual- and brand-level covariates with the exception of overall brand market share. 
Table 4

Incidence rate ratio (IRR) for brand-specific average number of drinks per month as a function of exposure to brand-specific alcohol advertising on television (yes/no)

\begin{tabular}{llll}
\hline Exposure & IRR $^{\boldsymbol{a}}$ & $\mathbf{9 5 \%} \mathbf{C I}$ & p-value \\
\hline Any exposure (adstock) & 3.35 & $2.31,4.87$ & $<0.0001$ \\
Any exposure within the past month & 2.39 & $1.54,3.72$ & $<0.0001$ \\
\hline
\end{tabular}

